\title{
Power Driven Train
}

\author{
D. Laxma Reddy ${ }^{1}$, V. Manaswini ${ }^{2}$, N. Nagaveni ${ }^{3}$, P.Thejaswi ${ }^{4}$, \\ P.Purna Chander ${ }^{5}$ \\ ${ }^{I}$ (Assistant Professor, Department of Electronics and communication engineering, MLR Institute of technology, \\ Telangana, India.) \\ 2,3,4,5 (Department of Electronics and communication engineering, MLR Institute of technology,Telangana, \\ India.)
}

\begin{abstract}
Wireless power driven vehicle using magnetic resonance is the technology which doesn't require any fuel or electrical connection to run it in a specified path in fact it adopts a basic theory which has already been developed for at least 30 years with the term inductive power transfer. Wireless power transfer makes a remarkable change in the field of electrical engineering and eliminates the usage of conventional copper overhead wire for train. Based on this concept, the project is developed to transfer power to a robotic vehicle or electric car or electric train wirelessly. This project can also be used for high-power charging batteries in conventional electric cars wirelessly while on the run. So in order preserve the power, battery can be charged using solar panel fixed on the top of the car during sunny days and during cloudy climatic conditions battery can be charged through the induction coils which are placed in the car (secondary coil) and another one below the ground (primary coil).
\end{abstract}

Keywords: Magnetic resonance, Inductive power transfer, Solar panel, Rechargeable Battery.

\section{Introduction}

FOR energy, environment, and many other reasons, the electrification for transportation has been carrying out for many years. In railway systems, the electric locomotives have already been well developed for many years. A train runs on a fixed track. It is easy to get electric power from a conductor rail . However, for electric vehicles (EVs), the high flexibility makes it not easy to get power in a similar way. Instead, a high power and large capacity battery pack is usually equipped as an energy storage unit to make an EV to operate for a satisfactory distance. We are dependent on one form of energy or the other for fulfilling our needs. One such form of energy is the energy from fossil fuels. We use energy from these sources for generating electricity, running automobiles etc. but the main disadvantages of these fossil fuels are that they are not environmental friendly and they are exhaustible. To deal with these problems of fossil fuels, we need to look at the nonconventional sources of energy. With regard to this idea we have designed an electrical vehicle that runs on battery which is charged by solar panels during sunny days and by induction coils at cloudy days . the vehicle designed can be used for shuttle and short distances. As these vehicles form the future of the automotive industry, we need to concentrate on improving their design and making them cost effective. This vehicle/train is an initiative in this direction.

\section{Existing Method}

For energy, environment, and many other reasons, the electrification for transportation has been carrying out for many years. In railway systems, the electric locomotives have already been well developed for many years. A train runs on a fixed track. It is easy to get electric power from a conductor rail using pantograph sliders. Trains run using coal or copper wire a head or else through batteries. Not only trains all the vehicles will run using petrol, diesel, battery etc., which will cost high and releases harmful gases into air. All these sources (diesel,petrol,etc.) are non renewable resources .So in order to save all such resources for our future generations we have introduced electric car which runs on induction.

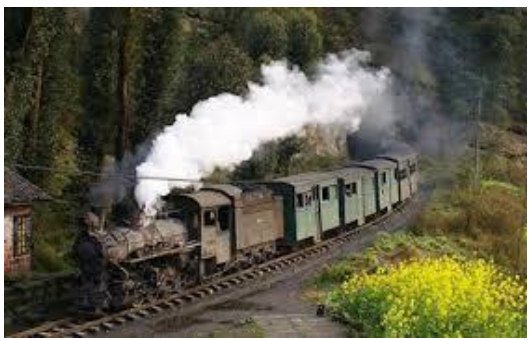

Fig:Coal trains 


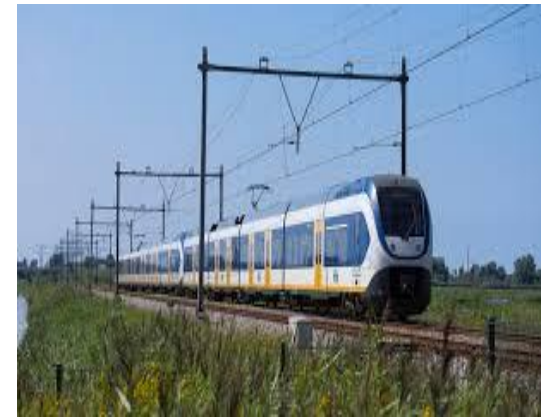

Fig: Copper wire ahead train

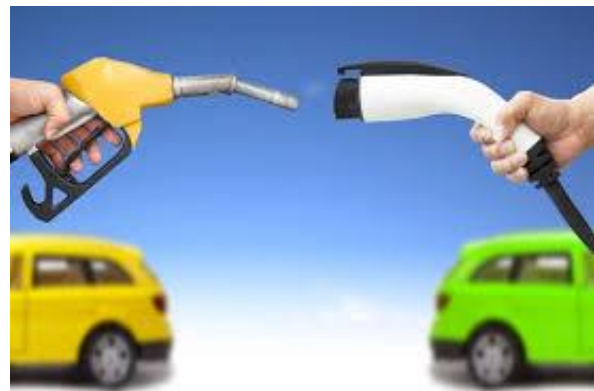

Fig:Petrol/Diesel vehicles

\section{III. proposed method}

This work is aimed towards the smart and cheapest way for travelling and to save the nonrenewable resources. The wireless power transfer (WPT) technology, which can eliminate all the charging troublesome, is desirable by the Electric vehicle (EV) owners. By wirelessly transferring energy to the EV, the charging becomes the easiest task. For a stationary WPT system, the drivers just need to park their car and leave. For a dynamic WPT system, which means the EV could be powered while driving; the EV is possible to run forever without a stop. Also, the battery capacity of EVs with wireless charging could be reduced to $20 \%$ or less compared to EVs with conductive charging. The main objective of this project is to transfer power wirelessly to one or more DC motors for an electric car or train without requiring any fuel or electrical connection to run it in a specified path.

\section{Block Diagram}

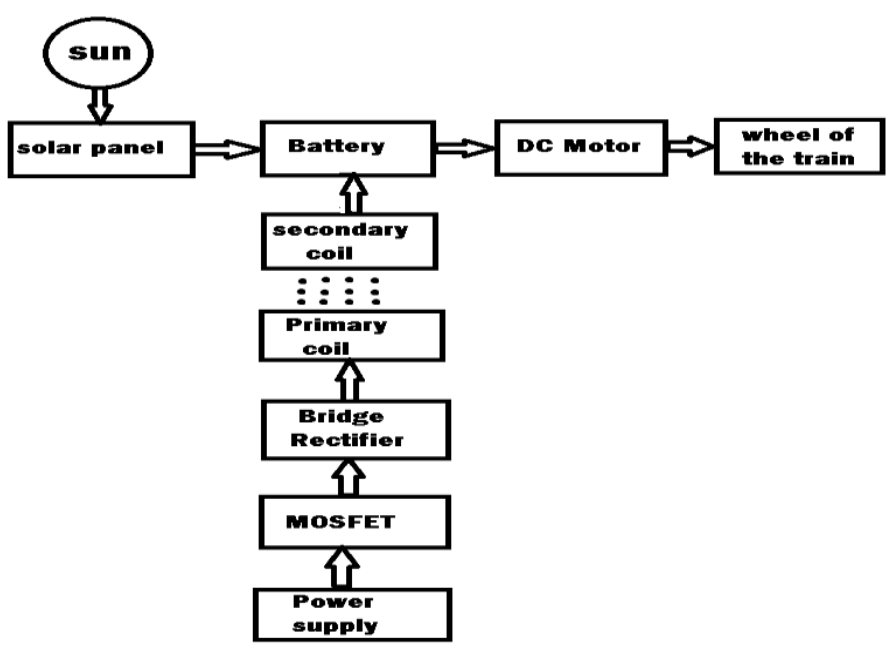

\section{Working:}

The main moto of our project is to charge a battery wirelessly so here in the above block diagram we are charging the battery in two ways one is through solar panels and the other is through the induction coil. During suuny days the battery will get charged through the solar panel. Here solar cell, or photovoltaic cell (previously termed "solar battery" ${ }^{[1]}$ ), is an electrical device that converts the energy of light directly into electricity by the photovoltaic effect, which is a physical and chemical phenomenon. ${ }^{[2]}$ This electrical energy 
is given to the battery to get charged. But during cloudy days ,sunlight is not sufficient to charge the battery so in order to overcome it we are using induction coil which is a type of electrical transformer used to produce high-voltage pulses from a low-voltage direct current (DC) supply. ${ }^{[3][4]}$ To create the flux changes necessary to induce voltage in the secondary coil, the direct current in the primary coil is induced.In between Power supply and primary coil there are MOSFET that is a type of field-effect transistor (FET). It has an insulated gate, whose voltage determines the conductivity of the device. This ability to change conductivity with the amount of applied voltage can be used for amplifying or switching electronic signals and bridge rectifiers which require rectified DC power supply for powering the various electronic basic components from available AC mains supply. Thus in this way magnetic resonance[5] is produced in between the secondary and primary coils and the battery gets charged with the electricity generated in the secondary coil.

Fortunately, such a solar transition is already happening. The Delhi Metro Rail Corporation (DMRC) has installed $500 \mathrm{kWp}$ worth of solar panels on one of its stations (Dwarka Sector 21). Given that the Delhi Metro has 140 stations, that alone - at an average of $200 \mathrm{~kW}$ - is $28 \mathrm{MW}$ of solar power, enough to power quite a few metro rail cars. Fortunately, such a transition is already happening. The Delhi Metro Rail Corporation (DMRC) has installed $500 \mathrm{kWp}$ worth of solar panels on one of its stations (Dwarka Sector 21). Given that the Delhi Metro has 140 stations, that alone - at an average of $200 \mathrm{~kW}-$ is $28 \mathrm{MW}$ of solar power, enough to power quite a few metro rail cars.

Running on solar power alone could reduce the consumption of diesel by up to 90,000 liters(annually) for a typical indian train. This implies a 2,340 ton reduction in co2 emissions per train per year (at an emission level of $2.6 \mathrm{~kg}$ of co2/liter of diesel)

\section{Conclusion}

In our project vechicle/train has charged using solar panel and induction coils which avoids the usage of petrol, diesel, coal etc. Fortunately, such a solar transition is already happening. The Delhi Metro Rail Corporation (DMRC) has installed $500 \mathrm{kWp}$ worth of solar panels on one of its stations (Dwarka Sector 21). Given that the Delhi Metro has 140 stations, that alone - at an average of $200 \mathrm{~kW}-$ is $28 \mathrm{MW}$ of solar power, enough to power quite a few metro rail cars. Fortunately, such a transition is already happening. The Delhi Metro Rail Corporation (DMRC) has installed $500 \mathrm{kWp}$ worth of solar panels on one of its stations (Dwarka Sector 21). Given that the Delhi Metro has 140 stations, that alone - at an average of $200 \mathrm{~kW}-$ is $28 \mathrm{MW}$ of solar power, enough to power quite a few metro rail cars.

\section{References}

[1]. Shockley, William; Queisser, Hans J. (1961). "Detailed Balance Limit of Efficiency of p-n Junction Solar Cells" (PDF). Journal of Applied Physics. 32 (3): 510. Bibcode:1961JAP....32..510S. doi:10.1063/1.1736034.

[2]. $\quad{ }^{\mathrm{b}}$ Solar Cells. chemistryexplained.com

[3]. John Archibald Fleming "Induction Coil". Encyclopadia Britannica, 11th Ed. 13. The Encyclopadia Britannica Co. 1911. pp. 502505. Retrieved October 13, 2014.

[4]. Jump up^ Collins, Archie F. (1908). The Design and Construction of Induction Coils. New York: Munn \& Co. p.98

[5]. Andre Kurs, Aristeidis Karalis,Robert Moffatt, J. D. Joannopoulos, Peter Fisher, Marin Soljacic. 2008. Wireless Power Transfer via Strongly Coupled Magnetic Resonances. Science. http://www.sciencemag.org/cgi/rapidpdf/1143254?ijkey=94ff.Ay4jRMqU\& keytype=ref\&siteid=sci 